Important note to readers

This content has been created for the entertainment of readers in the spirit of seasonal good humour and, on the whole, possesses not an ounce of truth. All persons, products, URLs and email addresses mentioned have been invented by the $B D$ J Editorial Team.

\begin{abstract}
An oral health routine yule love
Christmas' is a time of the year that we traditionally associate with over-indulgence - a period in which patients' adherence to oral healthcare routines may slip. A festive diet that features sugary dishes, such as Christmas pudding and mince pies, combined with frequent snacking between mealtimes on sweets and chocolates, is a recipe for rampant caries.

Now patients no longer have to choose between celebrating the festive season and good oral health thanks to the launch of No-L's new Yuletide range of dental healthcare products.

No-L's unique mouthwash range combines a state of the art formulation containing fluoride and chlorhexidine diacetate with the traditional tastes of Christmas, including Egg-nog, Sherry and Mulled Wine. Combine these with a range of Yuleflavoured toothpastes (available in Christmas Pudding, Mince Pie and Roast Turkey flavours) and limited-edition 'Tinsel' dental floss for the ultimate festive tooth care routine.

If you're concerned about Father Christmas's oral health, why not leave a tube of No-L Mince Pie toothpaste and a glass of Sherry mouthwash by the chimney this year? www.No-Limits.com
\end{abstract}

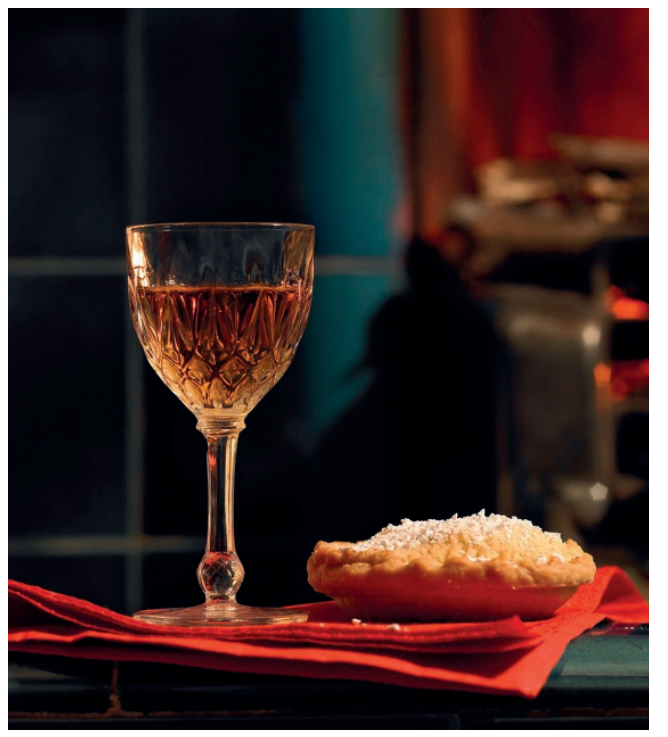

\title{
Mouth protection for your 147
}

Research shows that 1 in 1,200,000 snooker players suffer cue-related mouth injuries every year. Make sure you and your patients aren't that person by investing in the protection provided by a Cue Guard.

Cue Guards are specialist mouth guards designed to protect your teeth and gums from nasty injuries caused by errant cueing, slippery snooker balls, or trick shots gone awry. Tests consistently demonstrate that wearing a Cue Guard does not change your cueing action and shows no impact on potting averages. A range of colours and patterns are available and custom Cue Guards can be made to match waistcoats or to feature player nicknames.

No one wants to have to factor in mouth protection when working out the angles but, without Cue Guard, this can be a big concern for all snooker players - amateur and pros alike. ${ }^{1}$ Stan Davies, former World Snooker Champion known as the 'Pistol from Bristol,' has been using a Cue Guard for the last two

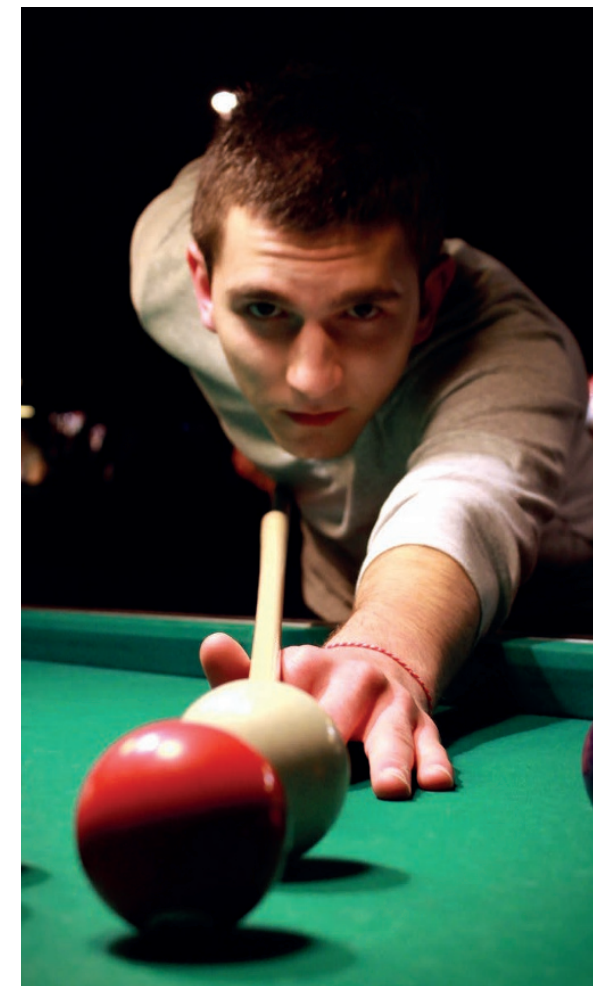

years and has found its made a real difference: 'It's so great. It's really taken the fear and danger out of the game for me. I used to hold back, terrified of knocking a tooth out or damaging my gums but the Cue Guard means I can now cue without constraints. If only I'd had this years ago I think I would've won more championships. I love how cool it looks too. I've had a personal mouth guard made with a giant pistol on it - absolutely terrifies my opponents!'

If you would like your dental practice to partner with Cue Guard so they can help you to deliver safety to your snookerplaying patients, visit the website at www. cueguard.com or contact Sales Executive, Dennis Higgins, by emailing 147protector@ cueguard.com.

A version of the Cue Guard, the Rack 'em up Guard, specially designed for pool players, is also in progress; watch this space!

1. Roisentul A, Gilbey P, Pikkel J. Remote penetrating orbital trauma due to a snooker cue through the mouth Dent Traumatol 2011; 27: 247-249. 